\title{
The effects of panel location, target size, and gender on efficiency in simple direct manipulation tasks
}

\author{
Rafal Michalski \\ Wroclaw University of Technology \\ Poland
}

\section{Introduction}

In recent years there was a big increase in the number of personal computers used worldwide. At the same time a lot of research have been conducted on usability of more and more sophisticated interactive systems. On the other hand some (e.g. Whittaker et al., 2000) have argued that too much focus was given to modern styles of human-computer interaction, since the usefulness of these proposals is very limited (Hartson, 1998). Simultaneously, the in-depth exploration of standard means of communication between human beings and computer programs are very often neglected.

The presented research involves the 'search and click' technique, which is a core component of a direct manipulation style of human-computer interaction (Shneiderman, 1982, 1983). Although currently there exist many other methods, the direct manipulation is still one of the most popular, especially among graphical interfaces. The study described in this publication may be situated in the trend of research related both to visual search and visually controlled motor activity (compare Grobelny et al., 2005; Michalski et al., 2006; Michalski \& Grobelny, 2008). This area is a combination of the traditional Fitts' approach (Fitts, 1954; Fitts \& Peterson, 1964), in which only the movement time related to graphical object selection is taken into account, and the situation where the time of visual search for a particular target among the group of distractors is of a main concern. The rationale of including these two activities simultaneously in the experimental setup arise from the observations presented in the work of Hoffmann \& Lim (1997). The researchers argue that concurrent decision and movement tasks are complex, and they should not be analysed separately. Their suggestions were backed up by experimental results. Additionally, there are some evidence at the neural level (Wurtz et al., 1982; Kustov \& Robinson, 1996; Colby \& Goldberg, 1999) suggesting that a manual response to a stimulus may influence the cognitive processes.

This study is mainly focused on the problem of graphical panel position on the screen and its impact on the accomplishment of simple 'search and click' tasks. Despite some previous works dealing with this subject, there are still several issues that need to be addressed. The earlier research results are not always consistent. Let us take for instance locations of web site menus. McCarthy et al. (2003) demonstrated that the left menu location is faster 
searched, but if the user performed another visual search task in the same web page, this advantage was not observed. In the study of Kalbach \& Bosenick (2004), the menu location factor did not significantly influence the mean acquisition times either. The inconsistencies also exist, when the visual search of simple graphical objects is concerned (Michalski et al., 2006).

The prior studies in the HCI field discussed mostly left and right upper corner locations (McCarthy et al., 2003; Kalbach \& Bosenick, 2004; Michalski et al., 2006) and other positions were rarely examined. Among the works related to other than left and right screen locations of searched targets there are investigations of Campbell \& Maglio (1999), Schaik \& Ling (2001), and Pearson \& Schaik (2003). The study of Campbell \& Maglio (1999) demonstrated that the shortest mean response times were observed for the stimuli placed in the upper left corner of the screen, and the longest for targets in the lower right corner. Schaik \& Ling (2001) in their investigation showed that menus having the same contrast were operated the slowest in the bottom position, and that the reaction times for right located targets were significantly slower than in the case of left and top positions. Later in a quite similar paper, Pearson \& Schaik (2003) obtained similar selection times both for left and right menus as well as for top and bottom ones. The further analysis showed also, that there was meaningful difference between grouped results for left and right locations and grouped top and bottom. The side positioned menus occurred to be worse in terms of the selection speed than both top and bottom layouts.

The other area of interest discussed in the current research concerns possible differences between male and female computer users in executing simple direct manipulation tasks that require some cognitive effort. Gender differences in performing various types of cognitive task have been a topic of multiple studies in the psychology and neuropsychology fields (e.g. Harasty et al., 1997; Adam et al., 1999; Gur et al., 1999; Weiss et al., 2003; Blatter et al., 2006; Reimers \& Maylor, 2006; Roalf et al., 2006; Walhovd \& Fjell, 2007). It is generally accepted that men do better in spatial and mathematical tasks, whereas women have better verbal ability (MacCoby \& Jacklin, 1974). However, the latest research and meta analyses of previous papers suggest these differences to be less salient than in the past (Hyde \& McKinley, 1997; Jorm et al., 2004).

When the discrepancies in accomplishing simple pointing activities are concerned, it is assumed that they are a result of different strategies used by both sexes. According to this approach, women perform better when the accuracy is analysed, while men are superior in tasks, where completion time is of a great concern (Ives et al., 1993; Peters \& Campagnaro, 1996; Warshawsky-Livne \& Shinar, 2002; Barral \& Debû 2004; Rohr, 2006a, 2006b). As it was outlined above, there has been a significant amount of research regarding gender differences in performing cognitive and motor tasks separately, however the studies treating these two conditions simultaneously are hardly to find.

The following sections describe a laboratory experiment that was designed and conducted to cast more light on the aforementioned matters. More specifically, this paper in an attempt to explain how square panel locations along with two panel item sizes affect the speed of executing simple search and click tasks. In addition, differences in task performance between sexes are examined. The obtained results are analysed and compared with the outcomes of previous studies. Limitations of this research as well as possible future works are also outlined. 


\section{Method}

\subsection{Participants}

Overall, forty Wroclaw University of Technology students volunteered in the study. There was an equal number of male and female participants. The students were within the age range of 21-25 years, and they worked with computer programs on a daily basis. They reported having a normal or corrected to normal visual acuity.

\subsection{Apparatus}

A computer program written in a MS Visual Basic ${ }^{\mathrm{TM}} 6.0$ environment was used to conduct the experiments. The research took place in teaching laboratories on uniform personal computers equipped with the same computer mice and 17" monitors of the CRT type. The resolution was set at 1024 by 768 pixels and a typical (default) computer mouse parameters were used.

\subsection{Experimental design}

The graphical panels being investigated comprised of 36 buttons arranged in a square with 26 Latin alphabet characters and ten Arabic numbers placed on these buttons. Two independent variables were manipulated: the graphical object size and panel location on the screen. Two different, commonly occurring in up-to-date computer programs, panel item sizes were used in the experiments. The side square button sizes equalled to 22 (small) and 38 pixels (large). Bolded Times New Roman font types in sizes of 12, and 24 pt were employed. The distance between the user and the screen was set approximately at $50 \mathrm{~cm}$, so the visual angles of these objects amounted to $0^{\circ} 41^{\prime}$, and $0^{\circ} 69^{\prime}$ respectively. The second factor was examined on four levels corresponding to the four corners of the computer screen. The panels were moved away from the screen edges by 18 pixels to minimize the effect of faster selection of items located at the screen borders (Farris et al., 2002, 2006; Jones et al., 2005).

The independent variables resulted in eight different experimental conditions: (two object sizes) $\times$ (four panel locations). A mixed model design was applied. The object size factor was treated within subjects whereas the other effect was examined between subjects. Each of the four groups of participants testing the four panel locations consisted of an equal number of males and females. The dependent variables being measured were the 'search and click' task completion time and the number of errors committed. The time was computed from when the START button was pressed, to when the object was clicked. The error occurred if a subject selected different than required graphical object.

\subsection{Procedure}

Before the examination the subjects were informed about a purpose and course of the experiment. The study started by filling out a general questionnaire concerned with personal data and computer literacy. Next, participants were asked to perform five attemptive trials. After the warm-up, the proper experiment took place. First, instruction dialogue window, presenting a START button and the target to be looked for, appeared. The searched layout was invisible at this instant. After the START button was clicked, the window disappeared and one of the examined panels was shown. The user was instructed 
to find as fast as possible the required object in the presented structure, and click it using a computer mouse. The instruction window was shown for each trial. The panels were displayed in a random order, different for every subject. Every student performed 10 trials for each of the examined configurations. Every 10 trials, an informative window including mean acquisition times and incorrect attempts was shown, and after clicking the OK button the examination was continued.

\section{Results}

\subsection{Selection times}

The subjects performed 800 trials altogether. The proper target item was localized and clicked in 781 cases. Excluding the error searches, the mean value amounted to $2248 \mathrm{~ms}$ with the standard deviation $1576 \mathrm{~ms}$ and mean standard error $56 \mathrm{~ms}$. The median was equal to $1793 \mathrm{~ms}$. The shortest selection time was $672 \mathrm{~ms}$, whereas the longest - $14591 \mathrm{~ms}$. Both the skewness and the kurtosis were decidedly different than the values of these parameters characteristic of the normal distribution and amounted to 2.7 and 12 respectively. The basic descriptive statistics for all the examined conditioned (without the mistakes) are presented in table 1.

\begin{tabular}{llllccccc}
\hline No. & $\begin{array}{l}\text { Target } \\
\text { size }\end{array}$ & $\begin{array}{l}\text { Panel } \\
\text { location }\end{array}$ & Gender & N & $\begin{array}{c}\text { Median } \\
(\mathbf{m s})\end{array}$ & $\begin{array}{c}\text { Mean } \\
(\mathbf{m s})\end{array}$ & $\begin{array}{c}\text { SE } \\
(\mathbf{m s})\end{array}$ & $\begin{array}{c}\text { SD } \\
(\mathbf{m s})\end{array}$ \\
\hline 1. & Small & Left-Bottom & Female & 50 & 1547 & 1938 & 153 & 1079 \\
2. & Small & Left-Bottom & Male & 49 & 2193 & 2880 & 319 & 2235 \\
3. & Small & Left-Top & Female & 49 & 1938 & 2463 & 211 & 1478 \\
4. & Small & Left-Top & Male & 48 & 1933 & 2465 & 302 & 2092 \\
5. & Small & Right-Bottom & Female & 50 & 1838 & 2252 & 189 & 1340 \\
6. & Small & Right-Bottom & Male & 49 & 1843 & 2314 & 233 & 1633 \\
7. & Small & Right-Top & Female & 49 & 1893 & 2426 & 238 & 1667 \\
8. & Small & Right-Top & Male & 48 & 1793 & 1992 & 150 & 1039 \\
9. & Large & Left-Bottom & Female & 50 & 1406 & 1853 & 189 & 1337 \\
10. & Large & Left-Bottom & Male & 48 & 1787 & 2334 & 252 & 1748 \\
11. & Large & Left-Top & Female & 49 & 2294 & 2832 & 322 & 2256 \\
12. & Large & Left-Top & Male & 48 & 1728 & 2247 & 210 & 1454 \\
13. & Large & Right-Bottom & Female & 48 & 1577 & 2154 & 215 & 1486 \\
14. & Large & Right-Bottom & Male & 50 & 1507 & 1826 & 161 & 1139 \\
15. & Large & Right-Top & Female & 49 & 1412 & 1935 & 175 & 1226 \\
16. & Large & Right-Top & Male & 47 & 1913 & 2078 & 142 & 971 \\
\hline
\end{tabular}

Table 1. Basic descriptive statistics for all examined conditions

The results regarding selection times were next analysed by means of the Generalized Linear Models (GZLM; Nelder \& Wedderburn, 1972) under the assumption that the dependent variable has the inverse Gaussian (IG) distribution. These assumptions are reasonable in light of the results presented by Michalski (2005) and taking into account the dependent variable descriptive data calculated for the present study. A three way ANOVA based on the GZLM was used for examining the factors of the user gender, panel location, and target sizes. 


\begin{tabular}{lrcl}
\hline Effect & df & Wald statistics (W) & \multicolumn{1}{c}{$\mathbf{p}$} \\
\hline Panel location (PLO) & 3 & 9.6 & ${ }^{*} 0.022$ \\
Item size (ISE) & 1 & 3.9 & ${ }^{*} 0.047$ \\
Gender (GEN) & 1 & 0.15 & 0.70 \\
PLO $\times$ ISE & 3 & 2.2 & 0.54 \\
PLO $\times$ GEN & 3 & 16.5 & ${ }^{*} 0.00089$ \\
ISE $\times$ GEN & 1 & 0.899 & 0.34 \\
PLO $\times$ ISE $\times$ GEN & 3 & 5.9 & 0.12 \\
\hline
\end{tabular}

* The results significant at a level 0.05

Table 2. GZLM analysis of variance results

The results of the analysis are presented in table 2 and showed that the panel location along with the item size factor are significant at the level of $a=0.05$. The effect of gender alone occurred not to be meaningful, however there was a significant interaction between gender and panel location factors. All other interactions were irrelevant.

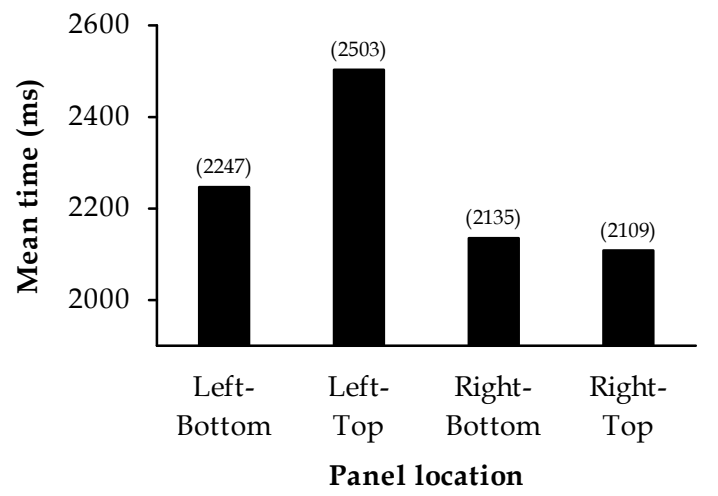

Fig. 1. Mean selection times depending on panel location $(\mathrm{df}=3, \mathrm{~W}=9.6, \mathrm{p}=0.022)$

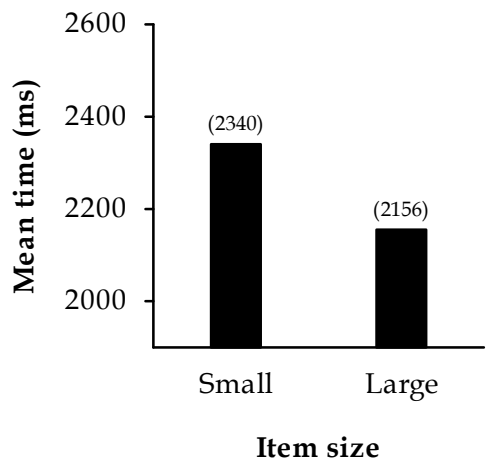

Fig. 2. Mean selection times depending on item size $(\mathrm{df}=1, \mathrm{~W}=3.9, \mathrm{p}=0.047)$

The mean acquisition times along with other basic statistics related to the panel location are presented table 3 and illustrated in fig. 1 . The layouts positioned on the right hand side of the computer screen, both top and bottom were operated the fastest, and the difference between their mean selection times were insignificant $(\mathrm{df}=1, \mathrm{~W}=0.049, \mathrm{p}=0.83)$. Among the structures located on the left, the bottom layouts were decidedly better $(\alpha=0.1)$ than the top ones $(\mathrm{df}=1, \mathrm{~W}=2.79, \mathrm{p}=0.095)$. The left top panel placement was the worst in terms of the selection speed, and the difference in average times between the best and the worst positions amounted to approximately $19 \%$ (394ms). 


\begin{tabular}{llccccccc}
\hline No. & Panel location & $\mathbf{N}$ & Median $(\mathbf{m s})$ & Mean $(\mathbf{m s})$ & SE $(\mathbf{m s})$ & SD $(\mathbf{m s})$ & Min $(\mathbf{m s})$ & Max $(\mathbf{m s})$ \\
\hline 1. & Left-Bottom & 197 & 1734 & 2247 & 120 & 1691 & 672 & 12148 \\
2. & Left-Top & 194 & 1930 & 2503 & 133 & 1853 & 688 & 14591 \\
3. & Right-Bottom & 197 & 1673 & 2135 & 101 & 1411 & 701 & 8001 \\
4. & Right-Top & 193 & 1772 & 2109 & 91 & 1264 & 701 & 8062 \\
\hline
\end{tabular}

Table 3. Results for the panel location factor $(\mathrm{df}=3, \mathrm{~W}=9.6, \mathrm{p}=0.022)$

The graphical illustration of mean acquisition times computed for the target size effect is presented in fig. 2, and the descriptive statistics are put together in table 4 . Mean times registered for panels consisting of large objects were substantially shorter than for their small counterparts. The discrepancy was equal $184 \mathrm{~ms}(8.5 \%)$.

\begin{tabular}{llccccccc}
\hline No. & Item size & $\mathbf{N}$ & Median (ms) & $\begin{array}{c}\text { Mean } \\
(\mathbf{m s})\end{array}$ & SE (ms) & SD (ms) & Min (ms) & Max (ms) \\
\hline 1. & Small & 392 & 1903 & 2340 & 82 & 1629 & 721 & 14591 \\
2. & Large & 389 & 1656 & 2156 & 77 & 1519 & 672 & 12578 \\
\hline
\end{tabular}

Table 4 . Results for the item size factor $(\mathrm{df}=1, \mathrm{~W}=3.9, \mathrm{p}=0.047)$

The GLZM analysis of variance revealed that there is an interaction between gender and panel location effects, so in fig. 3 and table 5 there are results presented separately for men and women taking part in the examination.

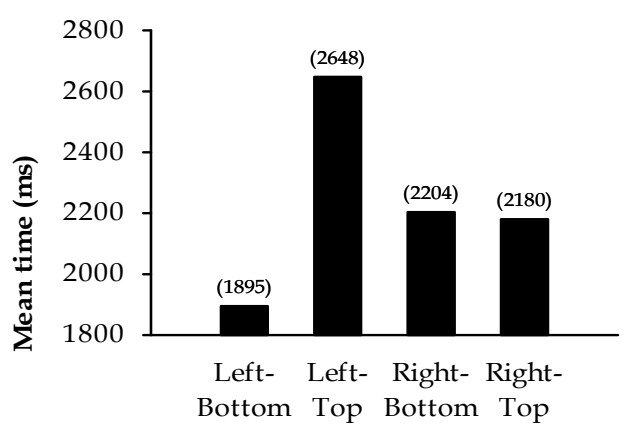

Females

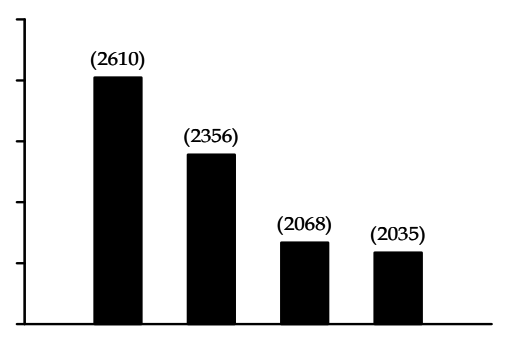

Left- Left- Right- RightBottom Top Bottom Top

\section{Males}

Fig. 3. Mean selection times depending on gender and panel location $(\mathrm{df}=1, \mathrm{~W}=16.5$, $\mathrm{p}=0.00089)$

The mean operation times for panels on right side of the screen were similar both for women and men as well as for top and bottom positions of these graphical structures. For layouts located on the left hand side of the monitor, females generally outperformed males 
$(\mathrm{df}=1, \mathrm{~W}=2.6, \mathrm{p}=0.1097)$ and left bottom panels were operated faster than left top configurations $(\mathrm{df}=1, \mathrm{~W}=3.3, \mathrm{p}=0.068)$.

\begin{tabular}{lllccccccc}
\hline No. & Gender & $\begin{array}{l}\text { Panel } \\
\text { location }\end{array}$ & N & $\begin{array}{c}\text { Median } \\
(\mathbf{m s})\end{array}$ & $\begin{array}{c}\text { Mean } \\
(\mathbf{m s})\end{array}$ & $\begin{array}{c}\text { SE } \\
(\mathbf{m s})\end{array}$ & $\begin{array}{c}\text { SD } \\
(\mathbf{m s})\end{array}$ & $\begin{array}{c}\text { Min } \\
(\mathbf{m s})\end{array}$ & $\begin{array}{c}\text { Max } \\
(\mathbf{m s})\end{array}$ \\
\hline 1. & Female & Left-Bottom & 100 & 1477 & 1895 & 121 & 1209 & 672 & 8406 \\
2. & Female & Left-Top & 98 & 2048 & 2648 & 193 & 1906 & 711 & 12578 \\
3. & Female & Right-Bottom & 98 & 1678 & 2204 & 142 & 1407 & 701 & 7210 \\
4. & Female & Right-Top & 98 & 1593 & 2180 & 149 & 1476 & 701 & 8062 \\
5. & Male & Left-Bottom & 97 & 2062 & 2610 & 205 & 2017 & 681 & 12148 \\
6. & Male & Left-Top & 96 & 1797 & 2356 & 183 & 1795 & 688 & 14591 \\
7. & Male & Right-Bottom & 99 & 1622 & 2068 & 143 & 1419 & 741 & 8001 \\
8. & Male & Right-Top & 95 & 1843 & 2035 & 103 & 1002 & 731 & 6630 \\
\hline
\end{tabular}

Table 5. Results for the interaction between gender and panel location $(\mathrm{df}=1, \mathrm{~W}=16.5$, $\mathrm{p}=0.00089)$

However, women had shorter mean selection times for left bottom structures than for left top ones, whereas men did better with left top panels than with left bottom configurations. This interaction between gender and left panel locations was also statistically significant $(\mathrm{df}=1, \mathrm{~W}=11.8, \mathrm{p}=0.000589)$.

\subsection{Errors}

A total of 19 errors were made by participants, which accounts for $2.4 \%$ of all performed trials. The percentages of mistakes registered during the examination are put together in table 6 . They are broken down by the examined factors.

\begin{tabular}{lc}
\hline Factor & Errors (\%) \\
\hline Panel location & \\
Left-Bottom & 1.5 \\
Left-Top & 1.5 \\
Right-Bottom & 3.5 \\
Right-Top & 3.0 \\
Item size & \\
$\quad$ Small & 2.0 \\
Large & 2.8 \\
Gender & \\
Female & 1.5 \\
Male & 3.3
\end{tabular}

\begin{tabular}{lccl}
\hline Factor & $\mathbf{d f}$ & $\boldsymbol{\chi}^{2}$ & \multicolumn{1}{c}{$\mathbf{p}$} \\
\hline Panel location & 3 & 2.75 & 0.43 \\
Item size & 1 & 0.49 & 0.49 \\
Gender & 1 & 2.64 & 0.104 \\
\hline
\end{tabular}

Table 7. Analysis of differences in the number of errors for examined factors

Table 6. Percentages of wrong selections

A nonparametric, Chi-square test was employed to verify the significance of differences in the number of wrong selections for the examined factors. The results of these analyses are presented in table 7 . The only meaningful difference in the number of wrong selections was observed for the gender factor. The significance level $\alpha=0.10$ was slightly exceeded in this 
case. Women committed decidedly less errors $(1.5 \%)$ than men did $(3.3 \%)$. The other two effects were irrelevant.

\section{Discussion}

Generally, the obtained results showed that the panel location and target item size factors considerably influenced the mean acquisition times. The gender effect was not meaningful, but the interaction between the gender and panel location was statistically significant.

\subsection{Panel location}

The results showed that the panel location factor considerably influenced the acquisition times. This outcome is generally consistent with the works of Campbell \& Maglio (1999), Schaik \& Ling (2001), McCarthy et al. (2003), Pearson \& Schaik (2003), and Michalski et al. (2006), where the stimuli position, one way or another, significantly influenced the response time. However, this result contradicts with the investigation presented by Kalbach \& Bosenick (2004), in which they did not observe the significant influence of the location factor. From among the aforementioned studies, the target locations used by Campbell \& Maglio (1999) were most similar to those employed in the described in this chapter experiment. Although, the location factor was significant in their experiment, the detailed results was contradictory with our findings. They explained the results by the nature of the stimulus, which was treated by participants as text to be read. In this paper experiments, it is hardly to associate the outcome to the reading habits, so maybe some other factors come into play. Possibly the obtained results were to some extent influenced by different ways of searching the target by men and women that manifested itself as the statistically significant interaction between location and gender factors. Of course, the discrepancies could have been caused also by a number of other issues including the different type target, screen resolutions, size of the screen, stimuli sizes, as well as the number of distractors and their arrangement.

\subsection{Target size}

The target object size effect was statistically meaningful. In the case of simple selection tasks where the target is constantly visible to the subject, the Fitts' law (Fitts, 1954; Fitts \& Peterson, 1964) applies. According to this well known formula, the movement time is affected by the object size along with the movement amplitude. However, the presented study involves additionally the search process, which may last decidedly longer than the time needed for reaching and clicking the target. In such a case, the Fitts' law may not be relevant. Nevertheless, some recent findings proved that bigger target objects shortened acquisition times (Michalski et al., 2006), and this finding was supported in the present investigation.

\subsection{Gender differences}

Though the effect of gender alone was not significant, the interaction between gender and panel location effects occurred to be meaningful. This relation was particularly visible for the panels positioned on the left hand side of the screen. Thus in general, the results support 
the hypothesis that there exists a significant difference between women and men in performing simple search and click tasks (at least for some locations). However, the obtained results seem a bit awkward and it is hardly to draw some reasonable conclusions. For instance, the better results for panels located in the left bottom in comparison with the left top corner obtained by females, could have been attributed to possible inappropriate chair seat height settings. But, if this was the case, so why were the women operation times for panel situated on the right hand side comparable? What is more, for the right placed panels men outperformed women in both bottom and top panel locations, so the interaction did not exist. Taking into consideration only the right locations, the present research outcomes to some extent support the assumption that men do better where the task accomplishment time is evaluated (Ives et al., 1993; Peters \& Campagnaro, 1996; Warshawsky-Livne \& Shinar, 2002; Barral \& Debû 2004; Rohr, 2006a, 2006b). But the differences are not statistically significant $(\mathrm{df}=1, \mathrm{~W}=1.34, \mathrm{p}=0.247)$. In light of such inconsistent results, these issues require undoubtedly further more detailed research.

\subsection{Incorrect selections}

The error analysis proved that males were more prone to make mistakes than females $(a=0.10)$, while the factors Panel location and Item size were irrelevant. The registered data confirm the suggestion that women put more attention to accuracy than male participants. The recorded mean error rate in this research $(2.4 \%)$ was generally comparable to the values obtained in other research. For example, in the research of Schaik \& Ling (2001), Pearson \& Schaik (2003), Grobelny et al. (2005), Michalski et al. (2006), Michalski \& Grobelny (2008), the mistakes occurred in less than $3 \%$ of all trials.

\subsection{Limitations and possible future works}

There is naturally a number of limitations related with this study. One of the most obvious weaknesses is the difficulty in interpreting especially those data, which are connected with the interaction between gender and the panel location. In light of these inconclusive results, additional studies seem to be necessary. Possibly, increasing the number of subjects or applying some eye tracking techniques would allow for more consistent conclusions.

It should also be stressed that almost all the participants were young and familiar with various computer programs, and were using computers on a daily basis, so their performance may substantially differ from the novice or elderly users. Additionally, the present investigation involved only one and very simple interaction technique, while the real interaction may require a combination of other ways of communicating with a computer. Also the choice of target icons may have an impact on the obtained results. Further research may include other graphical objects (e.g. icons from popular programs), different pointing devices, or subjective assessment of user preferences.

\section{Conclusions}

According to the obtained results during making the decisions about the design issues both the target size and location of a graphical panel should be considered. The obtained results also showed generally that in simple 'search and point' tasks, the gender factor should rather not be neglected. Although the influence seems not to be clear, the presented findings 
support the assumption of different ways of performing these kinds of tasks by men and women. As it was mentioned in the introductory section of this chapter, the obtained in this research differences may constitute a juxtaposition of the differences in performing the visually controlled motor tasks as well as discrepancies in executing cognitive tasks.

The presented research results enrich our knowledge in the area of simple pointing tasks combined with a visual search, and show the need for further studies concerned with the subject. However, because of some inconsistencies in the present and past research, one should be cautious in recommending any given design solution. In practice, decisions regarding the graphical features of toolbars should, obviously, take into account limitations of scientific investigations. Possibly, some additional research may be necessary to test the ecological validity of a particular proposal.

\section{References}

Adam, J.J., Paas, F.G.W.C., Buekers, M.J., Wuyts, I.J., Spijkers, W.A.C., \& Wallmeyer, P. (1999). Gender differences in choice reaction time: evidence for differential strategies. Ergonomics, 42(2), 327-335.

Barral, J., \& Debû, B. (2004). Aiming in adults: sex and laterality effects. Laterality, 9(3), 299-312.

Blatter, K., Graw, P., Munch, M., Knoblauch, V., Wirz-Justice, A., \& Cajochen, C. (2006). Gender and age differences in psychomotor vigilance performance under differential sleep pressure conditions. Behavioural Brain Research, 168(2), 312-317.

Campbell, C.S., \& Maglio, P.P. (1999). Facilitating navigation in information spaces: Roadsigns on the World Wide Web. International Journal of Human-Computer Studies, 50, 309-327.

Colby, C.L., \& Goldberg, M.E. (1999). Space and attention in parietal cortex. Annual Review of Neuroscience, 22, 319-349.

Farris, J.S., Johnson, B.R., \& Jones, K.S. (2006). Width guidelines for rectangular objects with penetrable and impenetrable borders. Behaviour \& Information Technology, 25(1), 83-90.

Farris, J.S., Jones, K.S., \& Anders, B.A. (2002). Factors affecting the usefulness of impenetrable interface element borders. Human Factors, 44(4), 578-591.

Fitts, P.M. (1954). The information capacity of the human motor system in controlling the amplitude of movement. Journal of Experimental Psychology, 49, 389-391.

Fitts, P.M., \& Peterson, J.R. (1964). Information capacity of discrete motor responses. Journal of Experimental Psychology, 67, 103-112.

Grobelny, J., Karwowski, W., \& Drury, C. (2005). Usability of Graphical icons in the design of human-computer interfaces. International Journal of Human-Computer Interaction, 18, 167-182.

Gur, R.C., Turetsky, B.I., Matsui, M., Yan, M., Bilker, W., Hughett, P., \& Gur, R.E. (1999). Sex differences in brain gray and white matter in healthy young adults: correlations with cognitive performance. Journal of Neuroscience, 19(10), 4065-4072.

Harasty, J., Double, K.L., Halliday, G.M., Kril, J.J., \& McRitchie, D.A. (1997). Languageassociated cortical regions are proportionally larger in the female brain. Archives of Neurology, 54(2), 171-176. 
Hartson, H.R. (1998). Human-computer interaction: Interdisciplinary roots and trends. The Journal of Systems and Software, 43, 103-118.

Hoffmann, E.R., \& Lim, J.T.A. (1997). Concurrent manual-decision tasks. Ergonomics, 40, 293-318.

Hyde, J.S., \& McKinley, N.M. (1997). Gender differences in cognition. results from metaanalyses. In P.J. Caplan, M. Crawford, J.S. Hyde, \& J.T.E. Richardson (Eds.), Gender Differences in Human Cognition (pp. 30-51). New York: Oxford University Press.

Ives, J.C., Kroll, W.P., \& Bultman, L.L. (1993). Rapid movement kinematic and electromyographic control characteristics in males and females. Research Quarterly for Exercise and Sport, 64(3), 274-283.

Jones, K.S., Johnson, B.R., \& Farris, J.S. (2005). GUI objects with impenetrable borders: Instruction (not practice) makes perfect. International Journal of Human-Computer Studies, 62(6), 687-712.

Jorm, A.F., Anstey, K.J., Christensen, H., \& Rodgers, B. (2004). Gender differences in cognitive abilities: The mediating role of health state and health habits. Intelligence, 32(1), 7-23.

Kalbach, J., \& Bosenick, T. (2003). Web page layout: A comparison between left- and rightjustified site navigation menus. Journal of Digital Information, 4, Article No. 153, 2003-04-28. Retrieved from http://jodi.tamu.edu/Articles/v04/i01/Kalbach/ on November 20, 2007.

Kustov, A.A., \& Robinson, D.L. (1996). Shared neural control of attentional shifts and eye movements. Nature, 384, 74-77.

MacCoby, E., \& Jacklin, C. (1974). The psychology of sex differences, Palo Alto: Stanford University Press.

McCarthy, J.D., Sasse, M.A., \& Riegelsberger, J. (2003). Could I have the menu please? An eye tracking study of design conventions. In Proceedings of HCI2003, Bath, UK, pp. 401-414.

Michalski, R. (2005). Komputerowe wspomaganie badań jakości ergonomicznej oprogramowania (Computer-aided research of software ergonomic quality). $\mathrm{PhD}$ thesis, Wroclaw University of Technology.

Michalski, R., Grobelny, \& J., Karwowski, W. (2006). The effects of graphical interface design characteristics on human-computer interaction task efficiency. International Journal of Industrial Ergonomics, 36, 959-977.

Michalski, R. \& Grobelny, J. (2008), The role of colour preattentive processing in humancomputer interaction task efficiency: a preliminary study, International Journal of Industrial Ergonomics, 38(3/4), 321-332.

Nelder, J.A., \& Wedderburn, R.W.M. (1972). Generalized linear models. Journal of the Royal Statistical Society A, 135, 370-384.

Pearson, R., \& Schaik, P. (2003). The effect of spatial layout of and link color in web pages on performance in a visual search task and an interactive search task. International Journal of Human-Computer Studies, 59, 327-353.

Peters, M., \& Campagnaro, P. (1996). Do women really excel over men in manual dexterity? Journal of Experimental Psychology/Human Perception \& Performance, 22(5), 1107-1112.

Reimers, S., \& Maylor, E. (2006). Gender Effects on Reaction Time Variability and Trial-toTrial Performance: Reply to Deary and Der (2005). Aging, Neuropsychology \& Cognition, 13(3/4), 479-489. 
Roalf, D., Lowery, N., \& Turetsky, B.I. (2006). Behavioral and physiological findings of gender differences in global-local visual processing. Brain and Cognition, 60(1), 3242.

Rohr, L.E. (2006a). Upper and lower limb reciprocal tapping: evidence for gender biases. Journal of Motor Behavior, 38(1), 15-17.

Rohr, L.E. (2006b). Gender-specific movement strategies using a computer-pointing task. Journal of Motor Behavior, 38(6), 431-437.

Schaik, P., \& Ling, J. (2001). The effects of frame layout and differential background contrast on visual search performance in web pages. Interacting with Computers, 13, 513-525.

Shneiderman, B. (1982). The future of interactive systems and the emergence of direct manipulation. Behaviour and Information Technology, 1, 237-256.

Shneiderman, B. (1983). Direct manipulation. A step beyond programming languages. IEE Computer, 16, 57-69.

Walhovd, K.B., \& Fjell, A.M. (2007). White matter volume predicts reaction time instability. Neuropsychologia, 45(10), 2277-2284.

Warshawsky-Livne, L., \& Shinar, D. (2002). Effects of uncertainty, transmission type, driver age and gender on brake reaction and movement time, Journal of Safety Research, 33(1), 117-128.

Weiss, E., Siedentopf, C. M., Hofer, A., Deisenhammer, E. A., Hoptman, M. J., Kremser, C., Golaszewski, S., Felber, S., Fleischhacker, W.W., \& Delazer, M. (2003). Sex differences in brain activation pattern during a visuospatial cognitive task: a functional magnetic resonance imaging study in healthy volunteers. Neuroscience Letters, 344(3), 169-172.

Whittaker, S., Terveen, L., \& Nardi, B.A. (2000). Let's stop pushing the envelope and start addressing it: A reference task agenda for HCI. Human-Computer Interaction, 15, 75-106.

Wurtz, R.H., Goldberg, M.E., \& Robinson, D.L. (1982). Brain mechanisms of visual attention. Scientific American, 246, 124-135. 


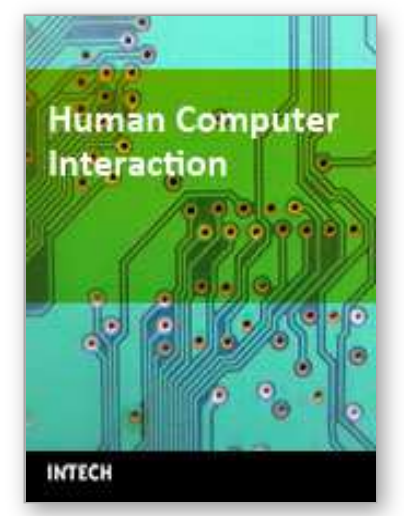

\section{Human Computer Interaction \\ Edited by loannis Pavlidis}

ISBN 978-953-7619-19-0

Hard cover, 522 pages

Publisher InTech

Published online 01, October, 2008

Published in print edition October, 2008

This book includes 23 chapters introducing basic research, advanced developments and applications. The book covers topics such us modeling and practical realization of robotic control for different applications, researching of the problems of stability and robustness, automation in algorithm and program developments with application in speech signal processing and linguistic research, system's applied control, computations, and control theory application in mechanics and electronics.

\section{How to reference}

In order to correctly reference this scholarly work, feel free to copy and paste the following:

Rafal Michalski (2008). The Effects of Panel Location, Target Size, and Gender on Efficiency in Simple Direct Manipulation Tasks, Human Computer Interaction, Ioannis Pavlidis (Ed.), ISBN: 978-953-7619-19-0, InTech, Available from:

http://www.intechopen.com/books/human_computer_interaction/the_effects_of_panel_location_target_size_ and_gender_on_efficiency_in_simple_direct_manipulation_t

\section{INTECH}

open science | open minds

\section{InTech Europe}

University Campus STeP Ri

Slavka Krautzeka 83/A

51000 Rijeka, Croatia

Phone: +385 (51) 770447

Fax: +385 (51) 686166

www.intechopen.com

\section{InTech China}

Unit 405, Office Block, Hotel Equatorial Shanghai

No.65, Yan An Road (West), Shanghai, 200040, China

中国上海市延安西路65号上海国际贵都大饭店办公楼 405 单元

Phone: +86-21-62489820

Fax: +86-21-62489821 
(C) 2008 The Author(s). Licensee IntechOpen. This chapter is distributed under the terms of the Creative Commons Attribution-NonCommercialShareAlike-3.0 License, which permits use, distribution and reproduction for non-commercial purposes, provided the original is properly cited and derivative works building on this content are distributed under the same license. 